\title{
A Vehicle Route Planning Method of Two-Phase Large-Scale Crowd Evacuation in Typhoon Relief Activities
}

\author{
Sha-lei Zhan $\mathbb{D D}^{1},{ }^{1}$ Liang Chen, ${ }^{2}$ Ping-Kuo Chen $\mathbb{D}^{\mathrm{D}},{ }^{3}$ and Yong Ye $\mathbb{D}^{4}$ \\ ${ }^{1}$ School of Management and E-Business, Zhejiang Gongshang University, Hangzhou 310018, China \\ ${ }^{2}$ College of Mathematics, Physics and Electronic Information Engineering, Wenzhou University, Wenzhou City, China \\ ${ }^{3}$ Department of Logistics Management, Wenzhou Business College, Wenzhou City, China \\ ${ }^{4}$ Department of Management, School of Public Health and Management, Wenzhou Medical University, Wenzhou City, China
}

Correspondence should be addressed to Ping-Kuo Chen; a1104100@ms23.hinet.net and Yong Ye; yong_ye@foxmail.com

Received 23 April 2019; Revised 12 July 2019; Accepted 24 July 2019; Published 31 August 2019

Academic Editor: Francisco J. Montáns

Copyright (c) 2019 Sha-lei Zhan et al. This is an open access article distributed under the Creative Commons Attribution License, which permits unrestricted use, distribution, and reproduction in any medium, provided the original work is properly cited.

\begin{abstract}
Large-scale crowd evacuation is an important measure guaranteeing the safety of disaster-stricken victims in typhoon relief activities. Decision-making related to antityphoon crowd evacuation must take full consideration of the destructive effect of typhoons and their secondary disasters, time urgency, and resource limitation. To give full play to limited vehicle resources, the influence of a typhoon and its secondary disasters on antityphoon evacuation are mainly manifested during the execution of evacuation tasks in this article. The shortest time spent in completing all evacuation tasks was taken as the objective. Then, a vehicle route selection model for two-phase large-scale antityphoon crowd evacuation was built under an uncertain environment, and a matrix encoding-based genetic algorithm was designed to solve the model. Under the background of Super Typhoon Meranti in 2016, the model and algorithm were applied to crowd evacuation in a typhoon in Xiamen for a simulated analysis. Results indicate that in typhoon relief activities, emergency decision makers can use the proposed method to acquire a scientific and reasonable route selection scheme for antityphoon crowd evacuation according to related typhoon disaster data.
\end{abstract}

\section{Introduction}

Typhoon disasters are one of the most serious natural disasters affecting human life. Research has shown that typhoons not only bring about direct disasters such as gales, rainstorms, and storm tides. Typhoons also give rise to derivative disasters such as torrential floods, landslides, debris flows, and waterlogging, thereby causing major loss of life, personal injuries, and property losses in the disaster chain [1]. Under the background of global warming, typhoon intensity is continuously enhanced, and the occurrence frequency of super typhoons also gradually increases [2]. With great power, strong destructive force, and broad scope of influence, a super typhoon seriously threatens public safety while bringing about major economic loss in coastal regions. Table 1 shows typhoons that have landed in China since 2000 and the losses they have caused. Long-term practices indicate that effective crowd evacuation is an important measure used to cope with super typhoon disasters and guarantee people's safety. Even though the accuracy of typhoon predictions today has evidently improved, related information cannot be accurately predicted yet. Large-scale antityphoon emergent crowd transfer decision-making is still faced with numerous uncertain factors during emergencies.

A number of scholars have studied emergent traffic evacuation in sudden major disasters, such as earthquakes [3], major biochemical accidents $[4,5]$, major fire accidents [6], and forest fires [4]. Such studies include crowd evacuation behaviors and decision-making, strategic evacuation planning, and evacuation simulation analysis. In crowd evacuation behaviors and decision-making, Solis et al. [5] selected 1,355 sample families from southeast and northwest Florida, USA, and studied their shelter-seeking and evacuation behaviors and decision-making demand under hurricanes Katrina, Dennis, and Wilma. Huang et al. [6] analyzed evacuation decision-making and evacuation time among residents during Hurricane Ike. Takagi et al. [7] 
TABLE 1: Typhoons that have landed in China since 2000 and losses they have caused.

\begin{tabular}{|c|c|c|c|c|c|}
\hline $\begin{array}{l}\text { Typhoon } \\
\text { name/no. }\end{array}$ & $\begin{array}{l}\text { Landing } \\
\text { area }\end{array}$ & $\begin{array}{l}\text { Maximum wind speed at the } \\
\text { center }(\mathrm{m} / \mathrm{s})\end{array}$ & $\begin{array}{c}\text { Number of dead or } \\
\text { missing } \\
\text { persons }\end{array}$ & $\begin{array}{l}\text { Number of } \\
\text { urgently } \\
\text { evacuated } \\
\text { persons }\end{array}$ & $\begin{array}{c}\text { Direct } \\
\text { economic } \\
\text { loss } \\
(\mathrm{RMB})\end{array}$ \\
\hline Yunna/200413 & Zhejiang & 45 & 186 & 468,000 & $\begin{array}{l}18.121 \\
\text { billion }\end{array}$ \\
\hline Saomei/200608 & Zhejiang & 60 & 483 & $1,559,000$ & $\begin{array}{c}19.44 \\
\text { billion }\end{array}$ \\
\hline Haikui/201211 & Zhejiang & 48 & 6 & $2,173,000$ & 2.09 billion \\
\hline $\begin{array}{l}\text { Rammasun/ } \\
201409\end{array}$ & $\begin{array}{c}\text { Hainan, Guangdong, and } \\
\text { Guangxi }\end{array}$ & 60 & 83 & 862,000 & $\begin{array}{c}38.48 \\
\text { billion }\end{array}$ \\
\hline Maria/201808 & Fujian and Zhejiang & 58 & 0 & 616,800 & 3 billion \\
\hline $\begin{array}{l}\text { Mangkhut/ } \\
201822\end{array}$ & $\begin{array}{c}\text { Guangdong, Guangxi, and } \\
\text { Hainan }\end{array}$ & 62.8 & 6 & $1,601,000$ & 5 billion \\
\hline
\end{tabular}

Data sources: National Climate Center of China, China Meteorological Administration, and China Weather Typhoon Net.

indicated that pedestrian evacuation when a typhoon caused a storm tide was of high risk.

Factors such as evacuation shelter selection and evacuation route selection are mainly studied in strategic evacuation planning. Robinson and Khattak [8] combined a decisionmaking model for evacuation route selection and microscopic traffic evacuation simulation to study evacuation strategy selection in Southeastern Virginia under the occurrence of hurricanes. Wu et al. [9] indicated that people decided their own evacuation routes according to their personal experience and traffic conditions and tended to evacuate to houses of their friends and relatives. Yin et al. [10] used a statistical method to study communication media selection by ordinary families in the evacuation process during Hurricane Ivan. Sadri et al. [14] built a hybrid logit model for evacuation route selection during hurricanes. When studying the issue of reverse lanes in traffic evacuation organization, Manki and Jonguk [15] designed a max flow-based route planning model. Under the background of a large-scale activity, Cai et al. [13] used minimum cost-maximum flow theory to build a network model for evacuation route selection.

In evacuation simulation analysis, Williams et al. [14] conducted a simulation study of the method used by coastal expressways for emergency evacuation during hurricanes through reverse roads. Edara et al. [15] used a network model to conduct a simulation analysis of a large-scale emergency evacuation during hurricanes for the $2,000 \mathrm{~km}$ road network in 10 cities. Yin et al. [16] proposed a Hurricane evacuation simulation method based on subject evacuation demand model, which included six evacuation decisions, including evacuation or nonevacuation, evacuation site selection, and evacuation mode selection. $\mathrm{Na}$ and Banerjee [17] proposed an agent-based discrete-event simulation model for sudden evacuation planning during natural disasters.

To sum up, a number of existing studies on large-scale antityphoon crowd evacuation have explored antityphoon evacuation behaviors, strategies, and simulations. Several studies on crowd evacuation route selection under super typhoon disasters are carried out under certain environments, but only a few studies have considered the influence of secondary disasters brought about by typhoons and disaster chains. Several decision-making method studies for antityphoon crowd evacuation vehicle routes assume that vehicles are used to evacuate people only between fixed retrieval depots and disaster-stricken points. Vehicle quantity restriction is used to express the evacuation ability constraint of retrieval depots without considering the dynamic driving process of evacuation vehicles in the evacuation process. Therefore, to avoid contradictions among typhoon destructiveness, time urgency, and resource limitation, this article considered the influence of typhoons and their secondary disasters on difficulties in evacuation vehicle transport. Given that evacuation vehicles can arrive at random retrieval depots and disaster-stricken sites to execute evacuation tasks, the shortest time spent in completing all evacuation tasks is taken as the objective. A vehicle route selection model for large-scale antityphoon crowd evacuation, which allowed evacuation vehicles to randomly select evacuation sites to execute their evacuation tasks under uncertain environments, was established. A matrix encoding-based genetic algorithm was designed to solve the model. Finally, against the background of Super Typhoon Meranti in 2016, the established model and algorithm were applied to large-scale antityphoon crowd evacuation scenarios for a simulation analysis.

\section{Decision-Making Model}

2.1. Assumptions and Symbols. As shown in Figure 1, largescale antityphoon evacuation action is divided into two phases in this article. In the first phase, victims are evacuated to temporary shelters. In the second phase, seriously injured people who need urgent treatment are continuously evacuated to the hospital, whereas uninjured people and mildly injured people stay at temporary shelters where they receive corresponding treatment and placement. In this way, respondents can maximize emergency resources like vehicles and minimize pressure on hospitals. Medical rescue is given to those who urgently need medical attention to effectively carry out crowd evacuation, enhance hospitals' treatment and rescue abilities, and improve emergency rescue efficiency.

Moreover, $n$ affected areas, $m$ temporary shelters for victims, $l$ hospitals, and $p$ vehicles (specifications of different 


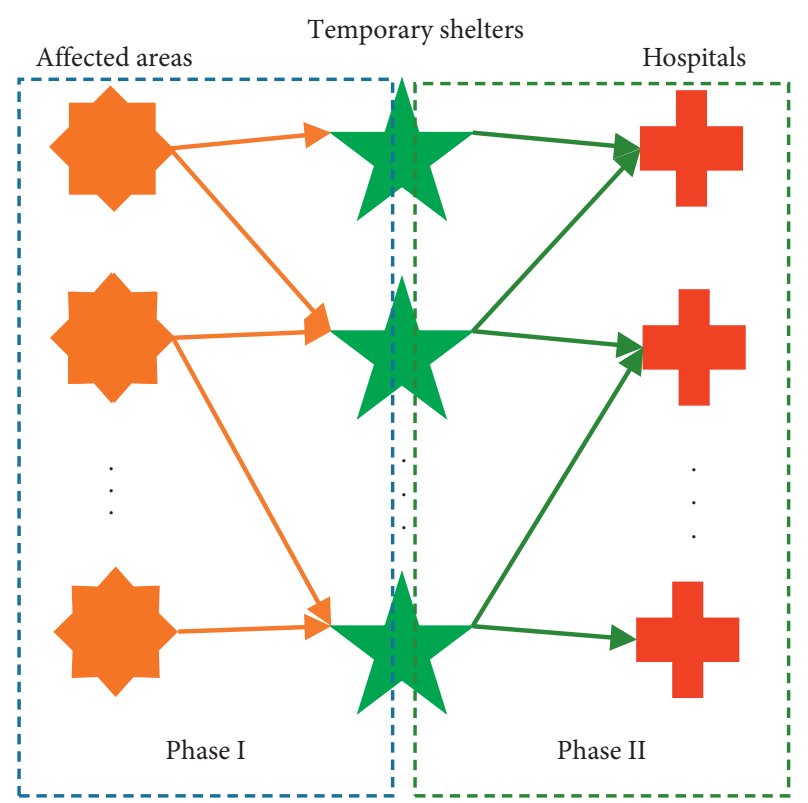

Figure 1: Schematic diagram of two-phase antityphoon crowd evacuation.

vehicles may vary), and the following definitions and assumptions are proposed:

Assumption 1. Vehicles can depart from affected areas, temporary shelters for victims, and hospitals to carry out evacuation tasks, and they are allowed to go to any affected area or temporary shelter to execute their tasks.

Assumption 2. After a vehicle completes its current evacuation task, another affected area or temporary shelter can be randomly selected to carry out the next evacuation task.

Assumption 3. Vehicles in affected areas and temporary shelters for victims give priority to carrying out evacuation tasks in Phase I.

Assumption 4. Vehicles like hospital ambulances only transport victims who need medical rescue and give priority to executing evacuation tasks in Phase II.

Assumption 5. Influences of typhoon disasters and their secondary disasters, like debris flow, landslide, and waterlogging, on evacuation tasks are mainly manifested by damaged roads that are used for evacuation. By-pass, rush repair, and other measures should be adopted for inaccessible roads.

Assumption 6. Driving time for vehicles to and from affected areas, temporary shelters for victims, and hospitals is influenced by a typhoon and its secondary disasters depending on the damage degree of this route. A high degree of damage requires a long driving time.

Definition 1. Departure is defined as the journey of transporting victims from affected areas to temporary shelters or hospitals. It also refers to the journey of transporting people in need of medical rescue from temporary shelters to hospitals.

Definition 2. Return is defined as the journey to affected areas or temporary shelters to transport victims and the journey to affected areas from temporary shelters to execute evacuation tasks.

Definition 3. Road impedance coefficient expresses the influence of a typhoon and its secondary disasters on running speed of evacuation vehicles, and its value is in direct proportion to the degree of road damage. The formula of road impedance coefficient from point $o_{v}^{k}$ to point $e_{v}^{k}$ is as follows:

$$
\rho\left(\theta_{o_{v}^{k} e_{v}^{k}}\right)=\frac{\alpha_{v}}{1-\theta_{o_{v}^{k} e_{v}^{k}}}
$$

where $\alpha_{v}$ is the vehicle road impedance coefficient. The driving ability of vehicles varies. Hence, different vehicles have different road impedance coefficients, which depends on the concrete environment. As a general rule, $\alpha_{v} \geq 1$.

Symbols used in this article are shown in Table 2.

2.2. Model. The minimum time needed to complete all evacuation tasks, specifically minimizing the time used by vehicles to execute evacuation tasks, is taken as the objective. The route decision-making model $\mathrm{M}$ for large-scale antityphoon crowd evacuation vehicles is as follows:

$$
\min T=\max _{v \in V}\left\{T_{v}+T_{v}^{\prime \prime}+T_{v}^{\prime \prime \prime}\right\}
$$

subject to

$$
T_{v}=f^{\prime}\left(s_{v}, \mathbf{r}_{v}, \boldsymbol{\theta}_{v}\right)=E\left[\sum_{o_{v}^{k}, e_{v}^{k} \in \mathbf{G}_{v}} \frac{d_{o_{v}^{k} e_{v}^{k}}}{s_{v}} \cdot \rho\left(\theta_{o_{v}^{k} e_{v}^{k}}\right)\right], \quad \forall v \in \mathbf{V},
$$$$
\begin{array}{r}
T_{v}^{\prime \prime}=f^{\prime \prime}\left(s_{v}, \mathbf{r}_{v}, \boldsymbol{\theta}_{v}\right)=E\left[\sum_{e_{v}^{k}, o_{v}^{k+1} \in \mathbf{G}_{v}} \frac{d_{e_{v}^{k} k_{v}^{k+1}}}{s_{v}} \cdot \rho\left(\theta_{e_{v}^{k} o_{v}^{k+1}}\right)\right], \\
\forall v \in \mathbf{V},
\end{array}
$$

$$
T_{v}^{\prime \prime \prime}=f^{\prime \prime}\left(\mathbf{r}_{v}\right)=t^{0} \cdot K_{v}, \quad \forall v \in \mathbf{V}
$$

$$
\begin{array}{r}
\frac{1}{1-\beta_{i}} \cdot \sum_{v \in \mathbf{V}} \sum_{o_{v}^{k} \in \mathbf{I} \cap \mathbf{G}_{v}} N_{o_{v}^{k} e_{v}^{k}}^{\prime k} \cdot Q_{v} \geq Q_{i} \quad \forall i \in \mathbf{I}, \\
\frac{1}{\beta_{i}} \cdot \sum_{v \in \mathbf{V}} \sum_{o_{v}^{k} \in I \cap \mathbf{G}_{v}} N_{o_{v}^{k} e_{v}^{k}}^{\prime \prime k} \cdot Q_{v} \geq Q_{i} \quad \forall i \in \mathbf{I},
\end{array}
$$

$\sum_{v \in \mathbf{V}} \sum_{o_{v}^{k} \in \mathbf{J} \cap \mathbf{G}_{v}}\left(N_{o_{v}^{k} e_{v}^{k}}^{\prime k}+N_{o_{v}^{k} v_{v}^{k}}^{\prime \prime k}\right) \cdot Q_{v} \leq Q_{j}^{\prime \prime}, \quad \forall j \in \mathbf{J}$, 
TABLE 2: Symbols.

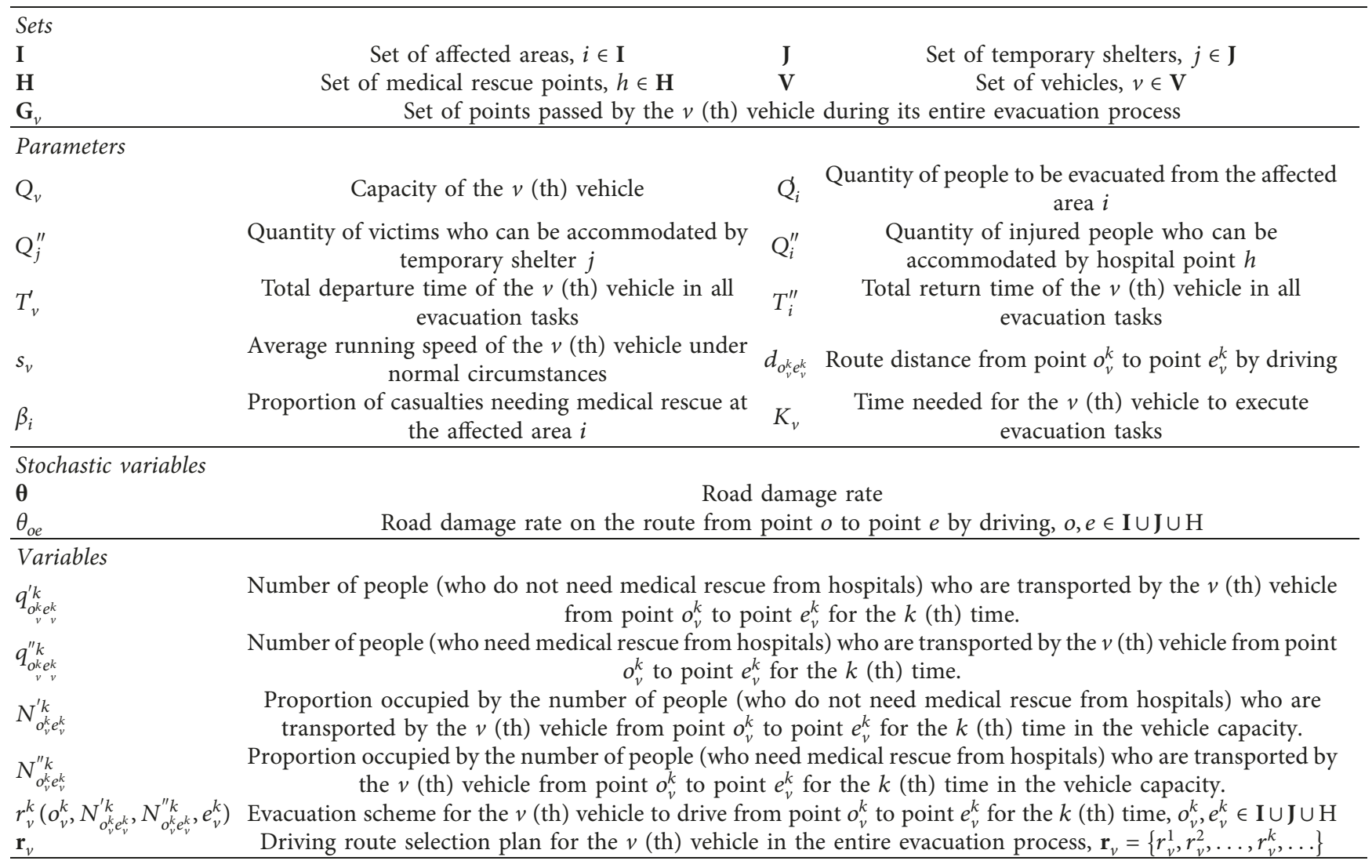

$$
\begin{aligned}
& \sum_{v \in \mathbf{V}} \sum_{o_{v}^{k} \in \mathbf{H} \cap \mathbf{G}_{v}}\left(N_{o_{v}^{k} v_{v}^{k}}^{\prime k}+N_{o_{v}^{k} v_{v}^{k}}^{\prime \prime k}\right) \cdot Q_{v} \leq Q_{h}^{\prime \prime \prime}, \quad \forall h \in \mathrm{H}, \\
& q_{o_{v}^{k} e_{v}^{k}}^{\prime k}=N_{o_{v}^{k} e_{v}^{k}}^{\prime k} \cdot Q_{v}, \quad \forall v \in \mathbf{V}, \\
& q_{o_{v}^{k} e_{v}^{k}}^{\prime \prime k}=N_{o_{v}^{k} e_{v}^{k}}^{\prime \prime k} \cdot Q_{v}, \quad \forall v \in \mathbf{V}, \\
& 0 \leq q_{o_{v}^{k} e_{v}^{k}}^{\prime k}+q_{o_{v}^{k} e_{v}^{k}}^{\prime \prime k} \leq Q_{v}, \quad \forall v \in \mathbf{V}, \\
& q_{o_{v}^{k} e_{v}^{k}}^{\prime}, q_{o_{v}^{k} e_{v}^{k}}^{\prime \prime k} \in Z^{+}, \quad \forall v \in \mathbf{V},
\end{aligned}
$$

where equation (3) is the value function of $T_{v}$, namely, the total departure time under the driving route $\mathbf{r}_{v}$ of the $v($ th) vehicle in the entire evacuation process. $\rho\left(\theta_{o_{v}^{k} e_{v}^{k}}\right)$ is computing the formula of road impedance coefficient, which refers to Definition 3. Equation (4) is total return time under the driving route $\mathbf{r}_{v}$ of the $v($ th) vehicle in the entire evacuation process. Equation (5) is the total time needed by victims to get on or off the $v($ th) vehicle in the entire evacuation process, and $t^{0}$ is the time needed by victims to get on or off a vehicle in an evacuation task. equation (6) is the constraint that people pending for evacuation who do not need medical rescue in all affected areas should be all evacuated. equation (7) is the constraint that all to-be- evacuated people who need medical rescue in all affected areas should be evacuated. equation (8) is the constraint that the total number of people evacuated to a temporary shelter should not exceed the total number of people accommodated by this temporary shelter. equation (9) is the constraint that the total number of people evacuated to a hospital should not exceed the total number of people accommodated by a hospital. equations (10) and (11) are value functions of the proportion of people transported by the $v$ (th) vehicle, which departs from point $o_{v}^{k}$ to point $e_{v}^{k}$. equation (12) is the constraint that all people should be evacuated at once. equation (13) is a symbol constraint.

\section{Solving Algorithm}

In 1959, Dantzig and Ramser [18] proposed a vehicle routing problem (VRP) for the first time. The optimal route realized objectives like shortest route, minimum cost, and least time consumed on the precondition that client demand was satisfied, whereas a vehicle team was responsible for distributing goods from the distribution center to clients. The VRP is a NP-hard problem [19]. The previous solving methods related to VRP can be divided into exact algorithms and heuristics, including minimum $k$-trees algorithm [20], genetic algorithm [21], comprehensive algorithm [22], and so on. The model built in this article was solved by using a matrix encoding-based genetic algorithm. 
3.1. Encoding Scheme and Fitness Function. In full consideration of two pragmatic encoding rules proposed by Dejong [26] and the model itself, the single evacuation task of a vehicle is set as the basic genetic unit. The sequence of all evacuation tasks of one vehicle constitutes a gene, and evacuation tasks of all vehicles constitute one chromosome. Chromosome structure is shown in Table 3.

To improve the algorithm efficiency, assuming that in the departure journey, none of the victims transported by vehicles need medical assistance in hospitals, the value function of the proportion occupied by the number of people transported by the $v\left(\right.$ th) vehicle from point $o_{v}^{k}$ to point $e_{v}^{k}$ for the $k$ (th) time is simplified as follows:

$$
\begin{gathered}
N_{o_{v}^{k} v e_{v}^{k}}^{\prime k}+N_{o_{v}^{k} v e_{v}^{k}}^{\prime \prime k}=1, \\
N_{o_{v}^{k} v_{v}^{k}}^{k} \cdot N_{o_{v}^{k} v e_{v}^{k}}^{\prime \prime k}=0 .
\end{gathered}
$$

The number of chromosome rows in the matrix is the number of vehicles, and the number $K$ of columns can be determined according to the number of victims needing evacuation, evacuation capacity, and so on. The fitness function is the objective function (2) in Phase I.

3.2. Crossover Operation. Two-column crossing method is used, and operation steps are as follows.

(i) $j^{\prime}, j^{\prime \prime}[1, K]$ is randomly selected, where $j^{\prime} \neq j^{\prime \prime}$ and $j^{\prime}<j^{\prime \prime}$.

(ii) Genetic codes from column $j^{\prime}$ to column $j^{\prime \prime}$ are exchanged between paternal chromosome matrices $P 1$ and $P 2$.

(iii) Constraint equations (6)-(9) are verified. If they hold true, then crossover operation ends.

(iv) Otherwise, the feasible operation will be executed.

3.3. Mutation Operation. Row mutation operation method is used, and the operation steps are as follows.

(i) $j^{\prime}, j^{\prime \prime}[1, p]$ is randomly selected, where $j^{\prime} \neq j^{\prime \prime}$ and $j^{\prime}<j^{\prime \prime}$.

(ii) Genetic codes of two rows are randomly generated to replace genetic codes of row $j^{\prime}$ and row $j^{\prime \prime}$.

(iii) Constraint equations (6)-(9) are verified. If they hold true, then mutation operation ends.

(iv) If not, feasible operation will be executed.

3.4. Selection Strategy. Expected value method and optimal individual retention strategies are adopted.

3.5. Feasible Chromosome Operation. Both subindividuals generated by crossover and mutation operations may generate unfeasible solutions. Under this circumstance, an initial genetic individual is randomly generated to replace this unfeasible individual.
3.6. Population Size and Initial Population. The study results of Jong (1975) indicate a good circumstance when population size is the same as or twice the size of the chromosome length. In full consideration of population diversity and computational efficiency, population size is selected as twice the chromosome length in this article.

3.7. Iterative Termination Strategy. The maximum number of iterations is set as $N_{\max }$. When the number of iterations reaches this value, the optimal individual is the output.

\section{Simulation Analysis of Antityphoon Crowd Evacuation during Super Typhoon Meranti}

4.1. Simulation Background. On September 10, 2016, Meranti was generated on the surface of the Northwest Pacific Ocean. Meranti landed in Taiwan and Xiamen (Fujian Province) in China at a super typhoon scale on September 15 with a maximum wind power of $52 \mathrm{~m} / \mathrm{s}$, inflicting major losses in Xiamen. Typhoon Meranti caused 28 deaths, 49 injuries, and 18 people to go missing after its landfall in mainland China. A total of 655,500 people were urgently evacuated in nine municipal-level cities and Pingtan comprehensive experimental zone and 86 counties (cities and districts) in the Fujian Province. Figure 2 shows the routes before and after Super Typhoon Meranti landed and routes predicted by different institutions. To deal with Super Typhoon Meranti, Xiamen evacuated typhoon-stricken victims from Dadeng (DD), Pubian (PB), Binhai $(\mathrm{BH})$, and Xike (XK) to Xiang'an (XA), Xiangshan (XS), and Xiamen University of Technology (XUT) and set No. 2 Hospital of Xiamen (N2HX) and No. 5 Hospital of Xiamen (N5HX) as medical rescue hospitals as shown in Figure 2.

4.2. Simulation Data. Each evacuation vehicle departing from hospitals could accommodate 10 people at most, and each vehicle departing from other points could accommodate 50 people at most. The proportion of typhoon-stricken victims who needed accept medical assistance in hospitals was $10 \%$, the road impedance coefficient of vehicles departing from hospitals was 1.5 . The road impedance coefficient of vehicles departing from affected areas and temporary shelters for victims was 1 , namely,

$$
\begin{array}{r}
\beta_{i}=0.05, \quad \forall i \in \mathbf{I}, \\
\alpha_{v}=\left\{\begin{array}{l}
1, \quad \forall v \in \mathbf{I} \cup \mathbf{J}, \\
1.5, \quad \forall v \in \mathrm{H} .
\end{array}\right.
\end{array}
$$

The road impedance coefficient follows uniform distribution from 0 to 1 , namely:

$$
\theta_{o_{v}^{k} e_{v}^{k}} \sim U(0,1), \quad \forall o_{v}^{k}, e_{v}^{k} \in \mathbf{I} \cup \mathbf{J} \cup \mathrm{H} .
$$

Quantities of victims and vehicle resources in affected areas are shown in Table 4. The total quantity of typhoonstricken victims and vehicle resources that could be accommodated by temporary shelters are shown in Table 5. 
TABLE 3: Chromosome structure.

\begin{tabular}{|c|c|c|c|}
\hline $\begin{array}{l}\mathbf{r}_{1}^{1}\left(o_{1}^{1}, N_{o_{1}^{1} e_{1}^{1}}^{\prime 1}, N_{o_{1}^{1} e_{1}^{1}}^{\prime \prime}, e_{1}^{1}\right) \\
\mathbf{r}_{2}^{1}\left(o_{2}^{1}, N_{o_{2}^{1} e_{v}^{1}}^{1}, N_{o_{1}^{1} e_{2}^{1}}^{\prime \prime}, e_{2}^{1}\right)\end{array}$ & $\begin{array}{l}\mathbf{r}_{1}^{2}\left(o_{1}^{2}, N_{o_{1}^{2} e_{1}^{2}}^{\prime 2}, N_{o_{1}^{2} e_{1}^{2}}^{\prime \prime 2}, e_{1}^{2}\right) \\
\mathbf{r}_{2}^{2}\left(o_{2}^{2}, N_{o_{2}^{2} e_{v}^{2}}^{2}, N_{o_{2}^{2} e_{2}^{2}}^{\prime \prime}, e_{2}^{2}\right)\end{array}$ & $\ldots$ & $\begin{array}{l}\mathbf{r}_{1}^{k}\left(o_{1}^{k}, N_{o_{0}^{2} e_{1}^{2}}^{\prime k}, N_{o_{0}^{2} e_{1}^{2}}^{\prime \prime}, e_{1}^{k}\right) \\
\mathbf{r}_{2}^{k}\left(o_{2}^{k}, N_{o_{2}^{k} e_{v}^{k}}^{k}, N_{o_{2}^{k} e_{2}^{k}}^{k}, e_{2}^{k}\right)\end{array}$ \\
\hline $\mathbf{r}_{p}^{1}\left(o_{p}^{1}, N_{o_{p}^{1} e_{p}^{1}}^{\prime}, N_{o_{p}^{1} e_{p}^{1}}^{\prime \prime}, e_{p}^{1}\right)$ & $\mathbf{r}_{p}^{2}\left(o_{p}^{2}, N_{o_{p}^{2} e_{p}^{2}}^{\prime 2}, N_{o_{p}^{2} e_{p}^{2}}^{\prime \prime 2}, e_{p}^{2}\right)$ & $\begin{array}{l}\cdots \\
\cdots\end{array}$ & $\mathbf{r}_{p}^{k}\left(o_{p}^{k}, N_{o_{p}^{k} p_{p}^{k}}^{\prime \cdots}, N_{o_{p}^{k} e_{p}^{k}}^{\prime \prime}, e_{p}^{k}\right)$ \\
\hline
\end{tabular}

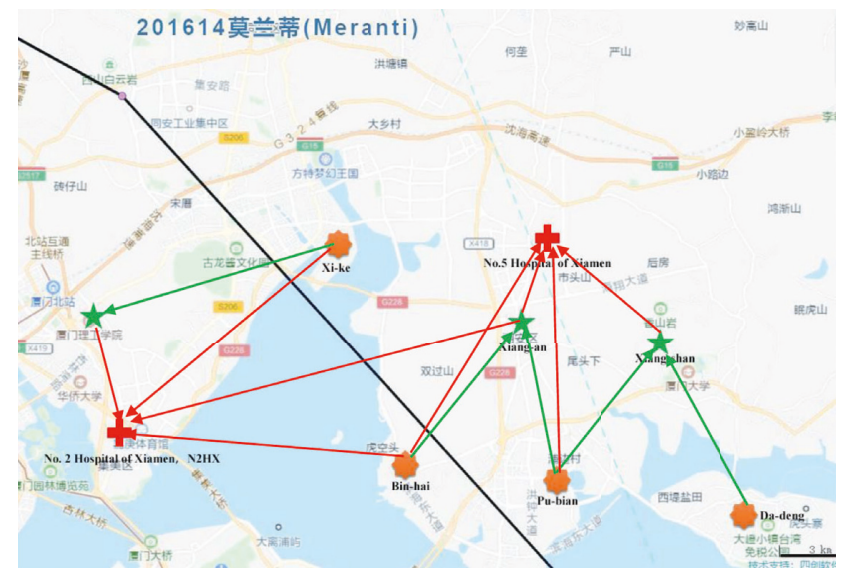

FIGURE 2: Schematic antityphoon evacuation graph during Super Typhoon Meranti. Note: The map was derived from Wenzhou Typhoon Net (http://www.wztf121.com/history.html).

TABLE 4: Numbers of to-be-evacuated victims and quantities of vehicle resources in affected areas.

\begin{tabular}{lcccc}
\hline & DD & PB & BH & XK \\
\hline Number of to-be-evacuated victims & 600 & 300 & 400 & 400 \\
Number of vehicles & 2 & 1 & 1 & 1 \\
\hline
\end{tabular}

TABle 5: Total number of victims and quantities of vehicle resources that can be accommodated by temporary shelters.

\begin{tabular}{lccc}
\hline & XS & XA & XUT \\
\hline $\begin{array}{l}\text { Total number of victims who can be } \\
\text { accommodated }\end{array}$ & 600 & 900 & 500 \\
Number of vehicles & 1 & 2 & 1 \\
\hline
\end{tabular}

Those which could be accommodated by hospitals are shown in Table 6. Vehicle running time and distance among affected areas, temporary shelters for victims, and hospitals under normal circumstances were obtained from Autonavi Navigation as shown in Table 7. In emergencies, the quantity of vehicle resources in affected areas, temporary shelters for victims, and hospitals are shown in Table 5 . Moreover, the time needed by victims to get on and off a vehicle in an evacuation task was set as $10 \mathrm{~min}$, namely, $t^{0}=10$.

4.3. Simulation Results. By using the proposed model and algorithm, and using MATLAB R2012a as the solver engine, we obtain the evacuation plan. The entire procedure took 12 minutes. We also recorded the best individuals of each generation. As shown in Figure 3, the
TABLe 6: Total number of patients and quantities of vehicle resources that can be accommodated by hospitals.

\begin{tabular}{lcc}
\hline & N2HX & N5HX \\
\hline $\begin{array}{l}\text { Total number of patients who can be } \\
\text { accommodated }\end{array}$ & 100 & 100 \\
Number of vehicles & 2 & 1 \\
\hline
\end{tabular}

TABLE 7: Average vehicle running time and distance among affected areas, temporary shelters for victims, and hospitals under normal circumstances $(\mathrm{min} / \mathrm{km})$.

\begin{tabular}{lccccc}
\hline & XS & XA & XUT & N2HX & N5HX \\
\hline DD & $26 / 18$ & $21 / 13$ & $47 / 39$ & $45 / 33$ & $30 / 22$ \\
PB & $25 / 14$ & $19 / 9$ & $43 / 30$ & $40 / 30$ & $26 / 19$ \\
BH & $28 / 17$ & $17 / 11$ & $35 / 25$ & $35 / 25$ & $23 / 17$ \\
XK & $36 / 25$ & $22 / 14$ & $20 / 12$ & $20 / 14$ & $21 / 10$ \\
XS & 0 & $18 / 10$ & $42 / 36$ & $38 / 32$ & $25 / 15$ \\
XA & $19 / 12$ & 0 & $29 / 22$ & $27 / 21$ & $13 / 7$ \\
XUT & $44 / 31$ & $31 / 21$ & 0 & $16 / 7.5$ & $35 / 21$ \\
\hline
\end{tabular}

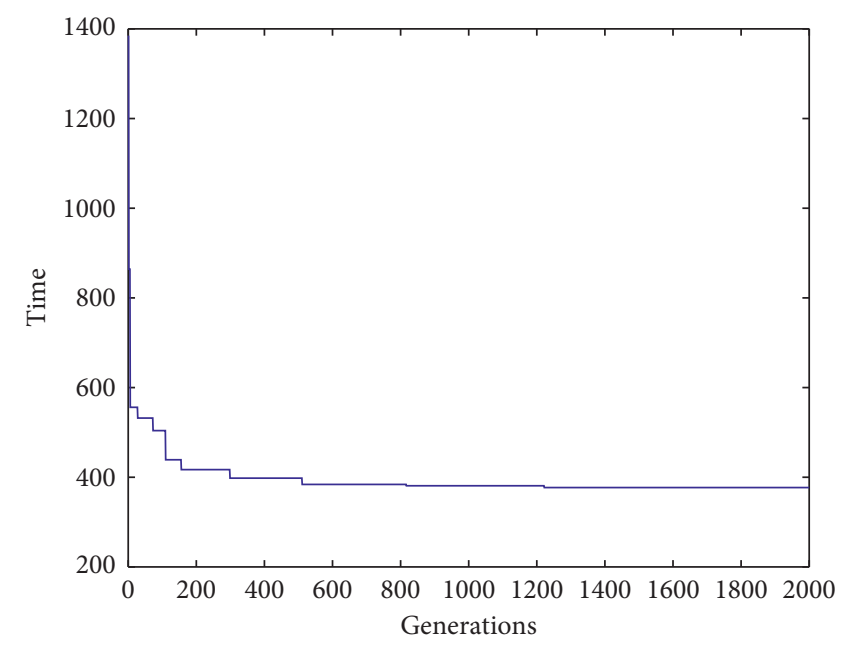

FIgURe 3: Total evacuation time during 2,000 generations.

total evacuation time of the best individuals in each generation was observed to decrease and tended to be stable after 1,221 generations. Thus, we set 2,000 as the iteration time.

Through 2,000 times of iteration, the optimal evacuation strategy with the total evacuation time of 376 minutes is obtained, and the concrete routes of 12 vehicles are shown in Table 8. In addition, the concrete number of people evacuated from affected areas to temporary shelters and hospitals and those who were evacuated from temporary shelters to hospitals are shown in Table 9. 
TABLE 8: Concrete routes of vehicles (time unit: $\mathrm{min}$ ).

\begin{tabular}{|c|c|c|}
\hline & Route & Time \\
\hline DD1 & $\mathrm{DD} \longrightarrow \mathrm{N} .5 \mathrm{HX} \longrightarrow \mathrm{DD} \longrightarrow \mathrm{XS} \longrightarrow \mathrm{DD} \longrightarrow \mathrm{XS}$ & 306 \\
\hline DD2 & $\mathrm{DD} \longrightarrow \mathrm{XS} \longrightarrow \mathrm{DD} \longrightarrow \mathrm{XS} \longrightarrow \mathrm{DD} \longrightarrow \mathrm{XS}$ & 290 \\
\hline PB1 & $\mathrm{PB} \longrightarrow \mathrm{XA} \longrightarrow \mathrm{PB} \longrightarrow \mathrm{XA} \longrightarrow \mathrm{PB} \longrightarrow \mathrm{XA} \longrightarrow \mathrm{PB} \longrightarrow \mathrm{XA}$ & 306 \\
\hline $\mathrm{BH} 1$ & $\mathrm{BH} \longrightarrow \mathrm{XA} \longrightarrow \mathrm{BH} \longrightarrow \mathrm{XA} \longrightarrow \mathrm{BH} \longrightarrow \mathrm{XA} \longrightarrow \mathrm{BH} \longrightarrow \mathrm{XA} \longrightarrow \mathrm{BH} \longrightarrow \mathrm{XA}$ & 356 \\
\hline XK1 & $\mathrm{XK} \longrightarrow \mathrm{XUT} \longrightarrow \mathrm{XK} \longrightarrow \mathrm{XUT} \longrightarrow \mathrm{XK} \longrightarrow \mathrm{XUT} \longrightarrow \mathrm{XK} \longrightarrow \mathrm{XUT}$ & 320 \\
\hline XS1 & $\mathrm{XS} \longrightarrow \mathrm{DD} \longrightarrow \mathrm{XS} \longrightarrow \mathrm{DD} \longrightarrow \mathrm{XS} \longrightarrow \mathrm{DD} \longrightarrow \mathrm{XS}$ & 342 \\
\hline XA1 & $\mathrm{XA} \longrightarrow \mathrm{PB} \longrightarrow \mathrm{XA} \longrightarrow \mathrm{BH} \longrightarrow \mathrm{XA} \longrightarrow \mathrm{BH} \longrightarrow \mathrm{XA} \longrightarrow \mathrm{BH} \longrightarrow \mathrm{XA} \longrightarrow \mathrm{N} .5 \mathrm{HX}$ & 356 \\
\hline XA2 & $\mathrm{XA} \longrightarrow \mathrm{DD} \longrightarrow \mathrm{XA} \longrightarrow \mathrm{DD} \longrightarrow \mathrm{XA} \longrightarrow \mathrm{DD} \longrightarrow \mathrm{XA} \longrightarrow \mathrm{DD} \longrightarrow \mathrm{XA}$ & 376 \\
\hline XUT1 & $\mathrm{XUT} \longrightarrow \mathrm{XK} \longrightarrow \mathrm{XUT} \longrightarrow \mathrm{XK} \longrightarrow \mathrm{XUT} \longrightarrow \mathrm{XK} \longrightarrow \mathrm{XUT} \longrightarrow \mathrm{XK}$ & 360 \\
\hline N.2HX1 & $\mathrm{N} .2 \mathrm{HX} \longrightarrow \mathrm{XUT} \longrightarrow \mathrm{N} .2 \mathrm{HX} \longrightarrow \mathrm{XUT} \longrightarrow \mathrm{N} .2 \mathrm{HX} \longrightarrow \mathrm{XUT}$ & 258 \\
\hline N.2HX2 & $\mathrm{N} .2 \mathrm{HX} \longrightarrow \mathrm{XUT} \longrightarrow \mathrm{N} .2 \mathrm{HX}$ & 106 \\
\hline N.5HX1 & $\mathrm{N} .5 \mathrm{HX} \longrightarrow \mathrm{XA} \longrightarrow \mathrm{N} .5 \mathrm{HX} \longrightarrow \mathrm{XA} \longrightarrow \mathrm{N} .5 \mathrm{HX} \longrightarrow \mathrm{XA} \longrightarrow \mathrm{N} .5 \mathrm{HX}$ & 264 \\
\hline
\end{tabular}

TABLE 9: Number of people evacuated in affected areas, temporary shelters for victims, and hospitals.

\begin{tabular}{lccccc}
\hline & XS & XA & XUT & N2HX & 0 \\
DD & 350 & 200 & 0 & 0 & N5HX \\
PB & 0 & 300 & 0 & 0 & 0 \\
BH & 0 & 0 & 400 & 0 & 0 \\
XK & 0 & - & - & 0 & 0 \\
XS & - & - & - & 0 & 0 \\
XA & - & - & & 40 & 0 \\
XUT & & & - & 0 & 0 \\
\hline
\end{tabular}

TABLE 10: Concrete routes of vehicles (time unit: $\mathrm{min}$ ).

\begin{tabular}{|c|c|c|}
\hline & Route & Time \\
\hline DD1 & $\mathrm{DD} \longrightarrow \mathrm{XS} \longrightarrow \mathrm{DD} \longrightarrow \mathrm{XS} \longrightarrow \mathrm{DD} \longrightarrow \mathrm{XS} \longrightarrow \mathrm{DD} \longrightarrow \mathrm{XS} \longrightarrow \mathrm{DD} \longrightarrow \mathrm{XS} \longrightarrow \mathrm{DD} \longrightarrow \mathrm{XS}$ & 572 \\
\hline DD2 & $\mathrm{DD} \longrightarrow \mathrm{XA} \longrightarrow \mathrm{DD} \longrightarrow \mathrm{XA} \longrightarrow \mathrm{DD} \longrightarrow \mathrm{XA} \longrightarrow \mathrm{DD} \longrightarrow \mathrm{XA} \longrightarrow \mathrm{DD} \longrightarrow \mathrm{XS} \longrightarrow \mathrm{DD} \longrightarrow \mathrm{XS}$ & 492 \\
\hline PB1 & $\mathrm{PB} \longrightarrow \mathrm{XA} \longrightarrow \mathrm{PB} \longrightarrow \mathrm{XA} \longrightarrow \mathrm{PB} \longrightarrow \mathrm{XA} \longrightarrow \mathrm{PB} \longrightarrow \mathrm{XA} \longrightarrow \mathrm{PB} \longrightarrow \mathrm{XA} \longrightarrow \mathrm{PB} \longrightarrow \mathrm{XA}$ & 456 \\
\hline $\mathrm{BH} 1$ & $\begin{array}{l}\stackrel{\mathrm{BH} \longrightarrow \mathrm{XA} \longrightarrow \mathrm{BH} \longrightarrow \mathrm{XA} \longrightarrow \mathrm{BH} \longrightarrow \mathrm{XA} \longrightarrow \mathrm{BH} \longrightarrow \mathrm{XA}}{\longrightarrow} \longrightarrow \mathrm{BH} \longrightarrow \mathrm{XA} \longrightarrow \mathrm{BH} \longrightarrow \mathrm{XA} \longrightarrow \mathrm{BH} \longrightarrow \mathrm{XA} \longrightarrow \mathrm{BH} \longrightarrow \mathrm{XA}\end{array}$ & 544 \\
\hline $\mathrm{XK} 1$ & $\begin{aligned} \mathrm{XK} \longrightarrow \mathrm{XUT} \longrightarrow \mathrm{XK} \longrightarrow \mathrm{XUT} \longrightarrow \mathrm{XK} \longrightarrow \mathrm{XUT} \longrightarrow \mathrm{XUK} \longrightarrow \mathrm{XKUT} & \longrightarrow \mathrm{XUT} \longrightarrow \mathrm{XUT} \longrightarrow \mathrm{XU} \longrightarrow \mathrm{XUT}\end{aligned}$ & 672 \\
\hline XS1 & $\mathrm{XS} \longrightarrow \mathrm{N} .5 \mathrm{HX}$ & 50 \\
\hline XA1 & $\mathrm{XA} \longrightarrow \mathrm{N} .5 \mathrm{HX}$ & 26 \\
\hline XA2 & - & 0 \\
\hline XUT1 & $\mathrm{XUT} \longrightarrow \mathrm{N} .2 \mathrm{HX}$ & 32 \\
\hline N.2HX1 & - & 0 \\
\hline N.2HX2 & - & 0 \\
\hline N.5HX1 & - & 0 \\
\hline
\end{tabular}

4.4. Discussion. Existing literature has developed the scheduling model by minimizing the total evacuation time [27]. This study changed its objective by determining the minimum time needed to complete all evacuation tasks (equation (2) as opposed to the minimum of the total evacuation time. The total evacuation time is defined as follows:

$$
\min T=\sum_{v \in V}\left\{T_{v}+T_{v}^{\prime \prime}+T_{v}^{\prime \prime \prime}\right\}
$$

By using the same data from Section 4.2, we run the simulation with the objective of equation (17). An optimal evacuation strategy was obtained, and its total evacuation time was 2,844 minutes. The routes of vehicles are shown in Table 10. The results of these two tests of total evacuation time and the time needed to complete all evacuation tasks are shown in Table 11. The evacuation strategy generated by equation (17) incurs less total evacuation time, but the time to complete all evacuation tasks is much longer. Four vehicles were not used in the strategy generated by equation (17). Therefore, the strategy generated by equation (2) is much more efficient than that of equation (17). 
TABLe 11: Comparison of the results of two tests (time unit: min).

\begin{tabular}{lcc}
\hline & Total evacuation time & Time needed to complete all evacuation tasks \\
\hline Results with equation (2) & 3,640 & 376 \\
Results with equation (17) & 2,844 & 672 \\
\hline
\end{tabular}

\section{Conclusions}

Super typhoons are one of the most common disasters that affect human life. Nearly every year, people die of typhoon disasters. To maximize limited vehicle resources within a limited time period, road impedance coefficient was introduced in this article to embody the influences of typhoons and their secondary disasters on evacuation tasks. The vehicle road impedance coefficient was used to embody the abilities of different vehicles in executing evacuation tasks. Evacuation vehicles were allowed to select any affected area or temporary shelter in the task execution process. To minimize the time needed by evacuation vehicles to complete evacuation tasks, a route selection model for antityphoon crowd evacuation vehicles was built, and a corresponding genetic algorithm was designed to solve it. Moreover, a large-scale crowd evacuation simulation of Super Typhoon Meranti indicated that the proposed method can provide emergency decision makers with a scientific and reasonable route selection scheme for antityphoon crowd evacuation vehicles.

The influence of typhoons and their secondary disasters are important factors in the execution of antityphoon crowd evacuation tasks, and their influence were also embodied by vehicle running time in this article. However, to-be-evacuated crowd structure, geological information, and geographic information in a disaster-stricken area and evacuation cost are also important factors influencing evacuation decision-making. Other related factors can be taken into consideration in future research to improve decision-making methods.

\section{Data Availability}

The data used to support the findings of this study are available from the corresponding author upon request.

\section{Conflicts of Interest}

The authors declare that they have no conflicts of interest.

\section{Acknowledgments}

This work was supported by the Zhejiang Provincial Philosophy and Social Science Program of China (grant no. 16ZJQN025YB), the National Natural Science Foundation of China (NSFC) (grant nos. 71601146, 71872131, and 71603237), the Zhejiang Provincial Philosophy and Social Science Program of China (grant no. 18NDJC198YB), and Zhejiang Provincial Natural Science Foundation of China (grant nos. LQ16G010005 and LY19G030004).

\section{References}

[1] R. A. Pielke, J. Gratz, C. W. Landsea et al., "Normalized hurricane damage in the United States: 1900-2005," Natural Hazards Review, vol. 9, no. 1, pp. 29-42, 2008.

[2] K. Emanuel, "Increasing destructiveness of tropical cyclones over the past 30 years," Nature, vol. 436, no. 31, pp. 686-688, 2005.

[3] M. Z. Duan, G. Chen, B. Dong et al., "Emergency rescue path selection model under uncertain information," Journal of Transportation Systems Engineering and Information Technology, vol. 17, no. 4, pp. 173-181, 2017.

[4] Z. Shuliang, C. Xiaoxia, L. Wenjun et al., "Optimization of field emergency evacuate and rescue route in nuclear accident.," Industrial Safety and Environmental Protection, vol. 44, no. 3, pp. 30-77, 2018.

[5] J. Li, Q. Q. Li, C. Q. He et al., "Study on emergency response for leakage accident of dangerous chemical gas based on GIS.," Journal of Safety Science and Technology, vol. 13, no. 11, pp. 66-72, 2017.

[6] N. J. Jin and Z. L. Mao, "Study on occupant evacuation model of multi-story building in fires," Industrial Safety and Environmental Protection, vol. 44, no. 4, pp. 1-14, 2018.

[7] S. Shahparvari, B. Abbasi, and P. Chhetri, "Possibilistic scheduling routing for short-notice bushfire emergency evacuation under uncertainties: an Australian case study," Omega, vol. 72, pp. 96-117, 2017.

[8] D. Solis, M. Thomas, and D. Letson, "Hurricane evacuation household making-decision: lessons from Florida," in Proceedings of the Selected Paper Prepared for Presentation at the Southern Agricultural Economics Association Annual Meeting, Atlanta, Georgia, January-February 2009.

[9] S.-K. Huang, M. K. Lindell, C. S. Prater, H.-C. Wu, and L. K. Siebeneck, "Household evacuation decision making in response to hurricane ike," Natural Hazards Review, vol. 13, no. 4, pp. 283-296, 2012.

[10] H. Takagi, S. Li, M. de Leon et al., "Storm surge and evacuation in urban areas during the peak of a storm," Coastal Engineering, vol. 108, pp. 1-9, 2016.

[11] R. M. Robinson and A. Khattak, "Evacuee route choice decisions in a dynamic hurricane evacuation context," Transportation Research Record: Journal of the Transportation Research Board, vol. 2312, no. 1, pp. 141-149, 2012.

[12] H.-C. Wu, M. K. Lindell, and C. S. Prater, "Logistics of hurricane evacuation in hurricanes Katrina and Rita," Transportation Research Part F: Traffic Psychology and Behaviour, vol. 15, no. 4, pp. 445-461, 2012.

[13] W. H. Yin, P. Murray-Tuite, and H. Gladwin, "Statistical analysis of the number of household vehicles used for hurricane Ivan evacuation," Journal of Transportation Engineering, vol. 140, no. 12, article 04014060, 2014.

[14] A. M. Sadri, S. V. Ukkusuri, P. Murray-Tuite, and H. Gladwin, "How to evacuate: model for understanding the routing strategies during hurricane evacuation," Journal of Transportation Engineering, vol. 140, no. 1, pp. 61-69, 2014.

[15] M. Manki and L. Jonguk, "Maximum throughput flow-based contraflow evacuation routing algorithm," in Proceedings of 
the Third International Workshop on Pervasive Networks for Emergency Management 2013, pp. 511-516, IEEE, San Diego, CA, USA, March 2013.

[16] Z. Cai, F. Ren, Y. Chi, X. Jia, L. Duan, and Z. Ding, "Multivehicles dynamic navigating method for large-scale event crowd evacuations," Geoinformatica, vol. 22, no. 2, pp. 435-462, 2018.

[17] B. M. Williams, A. P. Tagliaferri, S. S. Meinhold, J. E. Hummer, and N. M. Rouphail, "Simulation and analysis of freeway lane reversal for coastal hurricane evacuation," Journal of Urban Planning and Development, vol. 133, no. 1, pp. 61-72, 2007.

[18] P. Edara, S. Sharma, and C. McGhee, "Development of a largescale traffic simulation model for hurricane evacuationmethodology and lessons learned," Natural Hazards Review, vol. 11, no. 4, pp. 127-139, 2010.

[19] W. Yin, P. Murray-Tuite, S. V. Murray-Tuite, and H. Gladwin, "An agent-based modeling system for travel demand simulation for hurricane evacuation," Transportation Research Part C: Emerging Technologies, vol. 42, no. 5, pp. 44-59, 2014.

[20] H. S. Na and A. Banerjee, "Agent-based discrete-event simulation model for no-notice natural disaster evacuation planning," Computers \& Industrial Engineering, vol. 129, pp. 44-55, 2019.

[21] G. B. Dantzig and J. H. Ramser, "The truck dispatching problem," Management Science, vol. 6, no. 1, pp. 80-91, 1959.

[22] R. Goel and R. Maini, "A hybrid of ant colony and firefly algorithms (HAFA) for solving vehicle routing problems," Journal of Computational Science, vol. 25, pp. 28-37, 2018.

[23] M. L. Fisher, "Optimal solution of vehicle routing problems using minimum K-trees," Operations Research, vol. 42, no. 4, pp. 626-642, 1994.

[24] F. H. Hu, B. L. Ma, L. Yang, and W. Li, "Research on vehicle scheduling optimization in emergency material distribution based on improved genetic algorithm," Application Research of Computers, vol. 31, no. 10, pp. 2928-2932, 2014.

[25] M. Alinaghian and N. Shokouhi, "Multi-depot multi-compartment vehicle routing problem, solved by a hybrid adaptive large neighborhood search," Omega, vol. 76, pp. 85-99, 2018.

[26] K. Dejong, An analysis of the behavior of a class of genetic adaptive systems., Ph. D. thesis, University of Michigan, Ann Arbor, MI, USA, 1975.

[27] M. Y. Li, J. Wang, and H. Shen, "Optimization of evacuation routes planning algorithms for flood events," Journal of GeoInformation Science, vol. 18, no. 3, pp. 362-368, 2016. 


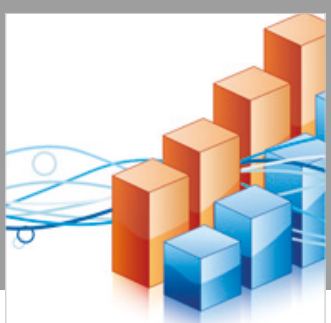

Advances in

Operations Research

\section{-n-m}
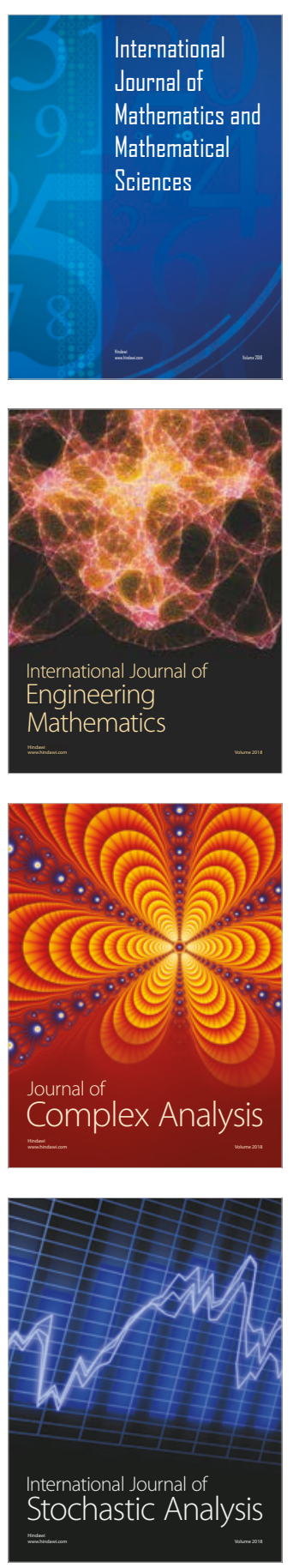
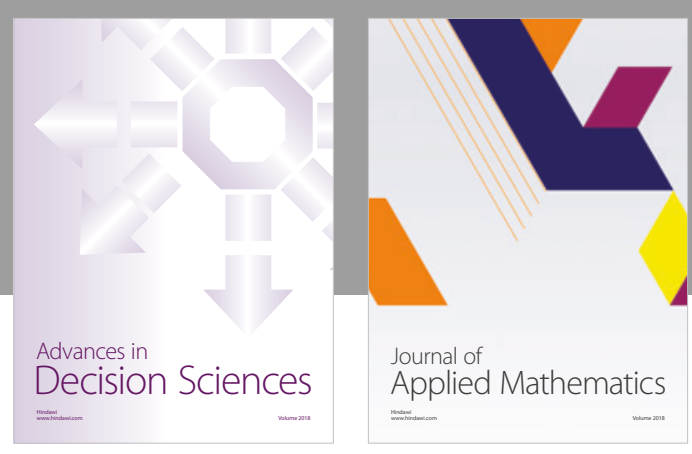

Journal of

Applied Mathematics
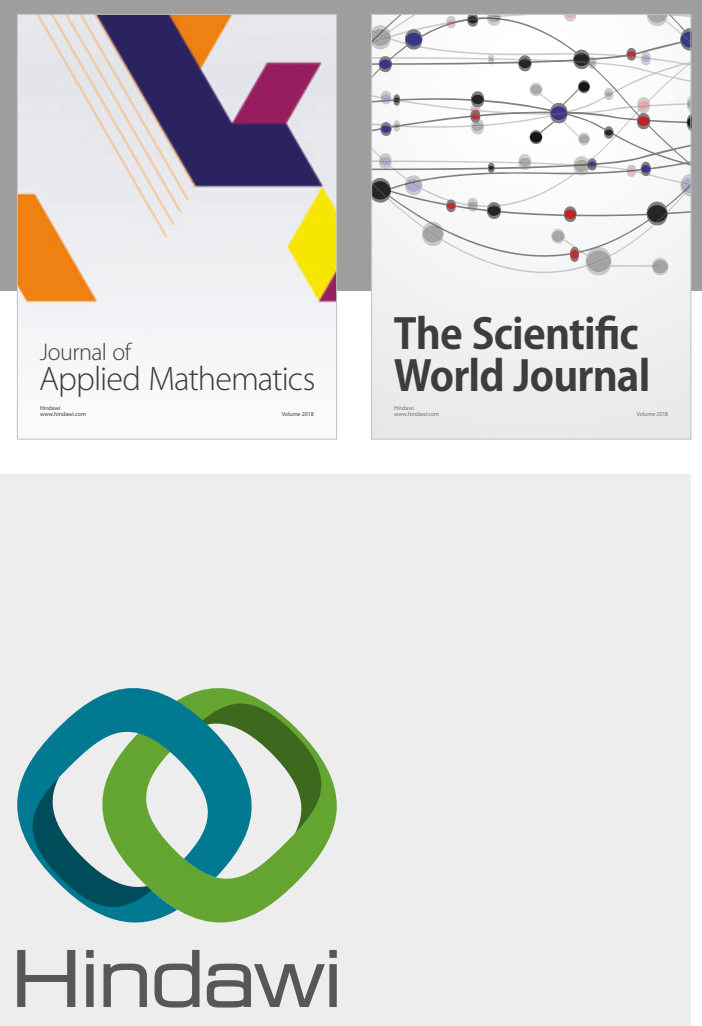

Submit your manuscripts at

www.hindawi.com

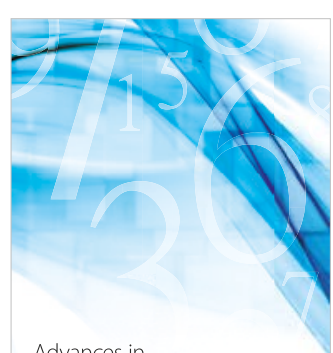

Advances in
Numerical Analysis
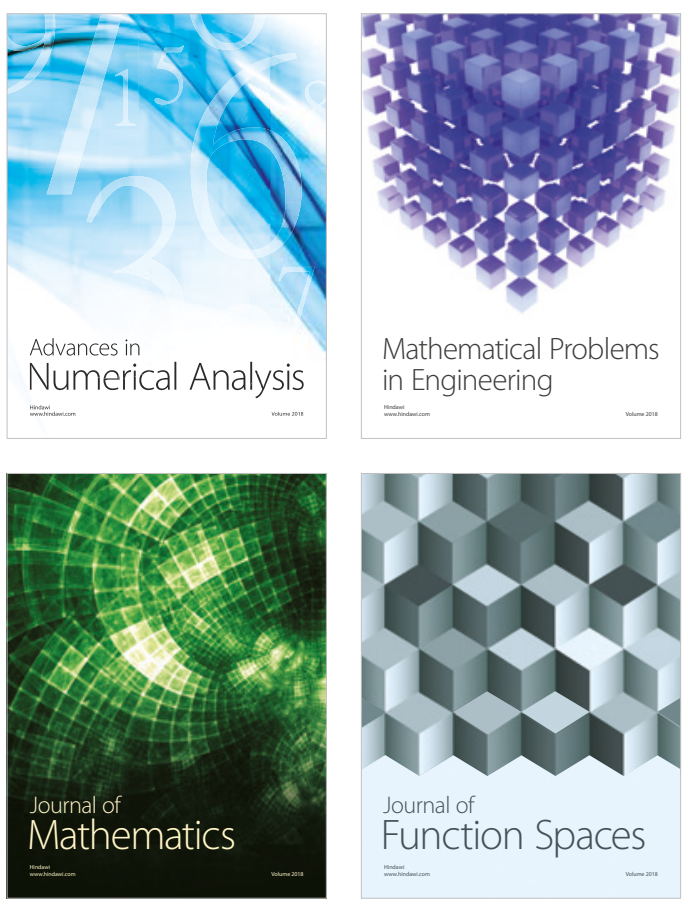

Mathematical Problems in Engineering

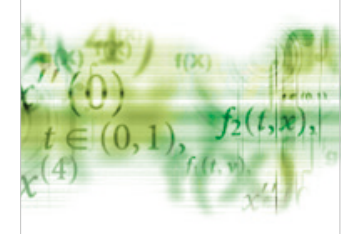

International Journal of

Differential Equations

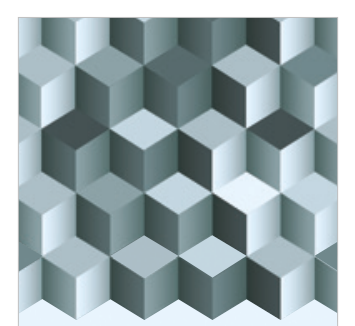

Journal of

Function Spaces

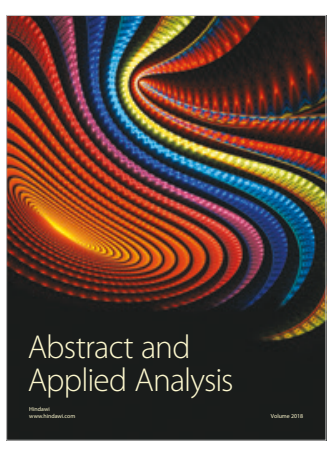

The Scientific

World Journal

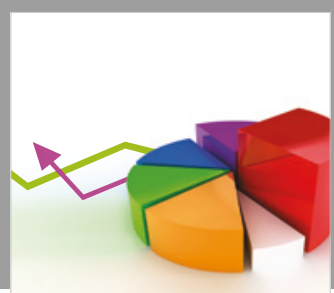

Journal of

Probability and Statistics
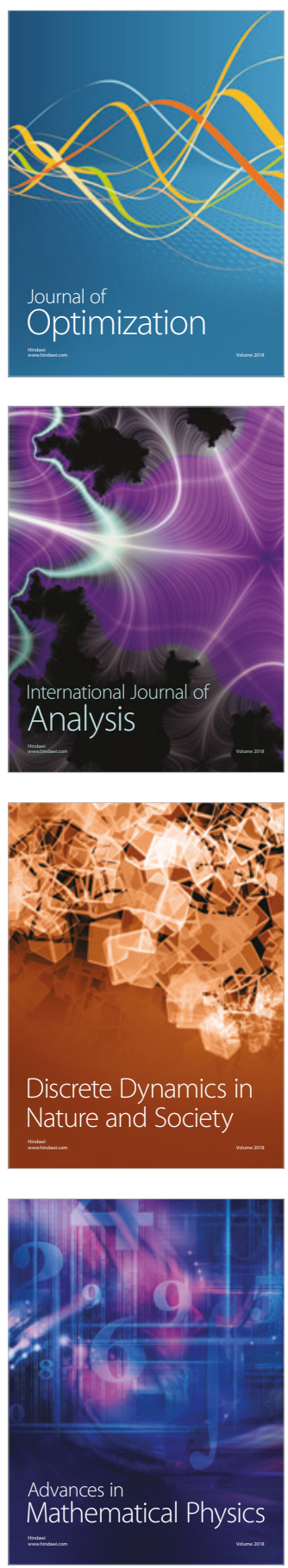